\title{
ISOLATED PULMONARY VALVULAR REGURGITATION COMPLICATED BY THYROTOXICOSIS
}

\author{
BY \\ ROBERT J. MARSHALL AND JOHN E. JONES \\ From the Department of Medicine, West Virginia University School of Medicine, Morgantown, West Virginia, U.S.A.
}

Pulmonary valvular regurgitation occasionally develops in the course of bacterial endocarditis due to erosion or perforation of the valve cusps. It also may occur in patients with chronic pulmonary hypertension secondary to obstructive lesions in the left side of the heart or in the pulmonary blood vessels. In these latter circumstances, the regurgitation is thought to be due to stretching of the valve ring, and it is manifested clinically by the well-known high-pitched early diastolic GrahamSteell murmur.

Isolated pulmonary valvular regurgitation is less common. It may result either from congenital absence or deformity of valve tissue or from idiopathic dilatation of the pulmonary artery. In the past six or seven years, increased clinical awareness of this condition, together with the opportunity for definitive diagnosis by cardiac catheterization and selective angiocardiography, has led to an increasing number of reported cases. Thus, while the first case diagnosed during life was reported in 1953, there are now 26 published cases (Laneve, Uesu, and Taguchi, 1962).

The most interesting physiological sequela of the valvular lesion is the hyperdynamic activity of the right ventricle. This is analogous with that found in atrial septal defect (Collins, Braunwald, and Morrow, 1960), a condition which is also characterized by an increase in the output of the right ventricle. The present case is, therefore, of unusual interest in that the patient had an additional disease, thyrotoxicosis, which also is associated with a hyperdynamic state of the circulation.

\section{Case Report}

The patient, a 23-year-old woman, was admitted to the West Virginia University Hospital on June 2, 1963 for evaluation of suspected recurrent thyrotoxicosis and also of a heart murmur. Two years previously she had a partial thyroidectomy for Graves' disease, performed elsewhere, with relief of symptoms. At that time a cardiac murmur was detected. There was no history of a murmur having been noted earlier in life. Recently she had a return of tachycardia together with increasing prominence of the eyes. There was no history of rheumatic fever.

On examination she had a slight lag of the upper eyelids. Palpation of the neck was difficult because of the thyroidectomy scar, but it was thought that some thyroid tissue extended under the manubrium sterni. The pulse was 96 a minute and regular and the blood pressure was $120 / 90 \mathrm{~mm}$. $\mathrm{Hg}$. There was a pronounced lift over the right ventricle, and pulsations of the pulmonary artery were readily felt in the second left intercostal space. The second component of a normally split second sound was moderately accentuated in the pulmonary area. There was an early systolic ejection click and murmur over the outflow portion of the right ventricle. A low-pitched diastolic murmur, separated from the second sound by a distinct interval, was heard best in the second left interspace and was transmitted down the left border of the sternum; it was not heard to the right of the sternum. The remainder of the examination was normal.

Fluoroscopy and x-ray films showed a dilated and extremely pulsatile main pulmonary artery with a moderately enlarged hyperdynamic right ventricle. The other cardiac chambers were of normal size, and the pulmonary vascular markings were not increased. The electrocardiogram was normal. The basal metabolic rate was +23 per cent. The serum protein-bound iodine in a sample of blood obtained three 
TABLE I

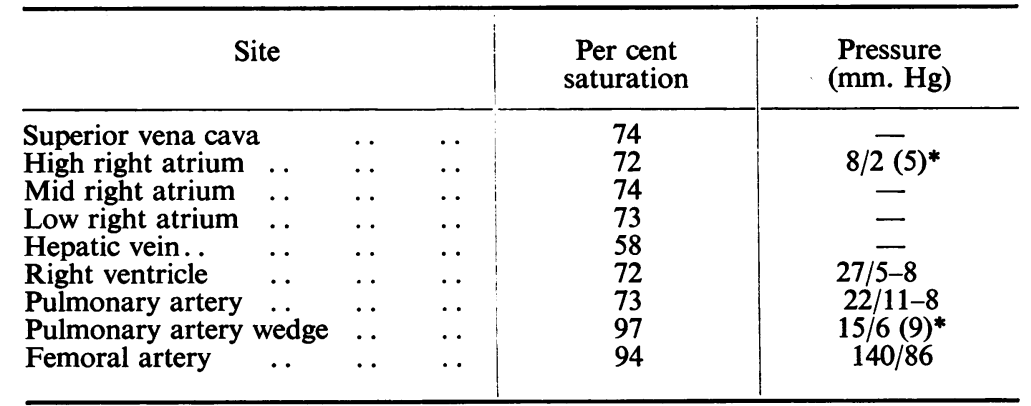

Oxygen consumption (S.T.P.D.) $272 \mathrm{ml}$. (171 ml./m.2).

Cardiac output (Fick) 6.63 1.; heart rate 100; effective stroke vol. $66 \mathrm{ml}$.

Cardiac output (dye) 7.25 1.; heart rate 105 ; effective stroke vol. $69 \mathrm{ml}$.

Body surface area 1.58 m.2 ; cardiac index (Fick) 4.2 1.; cardiac index (dye) 4.6 1.

Pulmonary vascular resistance 1 unit.

* Mean pressures in parentheses.

weeks previously was $10.0 \mu \mathrm{g} . / 100 \mathrm{ml}$. The 24 -hour uptake of ${ }^{131} \mathrm{I}$ was 56 per cent of the administered dose.

The clinical diagnosis was pulmonary valve regurgitation associated with dilatation of the main pulmonary artery.

Cardiac catheterization was undertaken in order to exclude the possibility of any associated lesion. The results are summarized in Table $\mathrm{I}$. The pulmonary artery pressure was equal to that in the right ventricle during the second half of diastole (Fig. 1). The remaining pressures were normal. The cardiac index was increased to 4.2 and $4.61 . / \mathrm{min} . / \mathrm{m} .{ }^{2}$ in two determinations, the normal range of values in our laboratory being 2.8 to $3.81 . / \mathrm{min} . / \mathrm{m}^{2}$ The heart rate was also increased, being 100 and 105 a minute, and the effective right ventricular stroke volume index (42 and $44 \mathrm{ml}$.) was within normal limits. The contours of indicator dilution curves, obtained by sampling at the femoral artery following injection of cardiogreen dye into the pulmonary artery, were normal (Fig. 2). The CL/CR ratio was $0 \cdot 2$ : this is the ratio of the least concentration (CL) of indicator between the initial circulation and the first recirculation to the maximal concentration during the recirculation phase (CR). The recirculation time (15 sec.) was short, a finding to be expected because of the increased cardiac output.

Angiocardiograms were obtained following injection of $30 \mathrm{ml} .90$ per cent Hypaque into the main pulmonary artery at its bifurcation. There was regurgitation of dye into the right ventricle during each diastole, with clearance of most of the dye during each subsequent systole. Marked changes in the calibre of the right pulmonary artery and its primary branches were evident between systole and diastole (Fig. 3A and 3B).

Treatment was started with propylthiouracil to control the thyrotoxicosis. When she was last seen, two months later, she appeared clinically euthyroid, the resting pulse rate was 76 a minute, and the right ventricle appeared to be less hyperdynamic than previously.

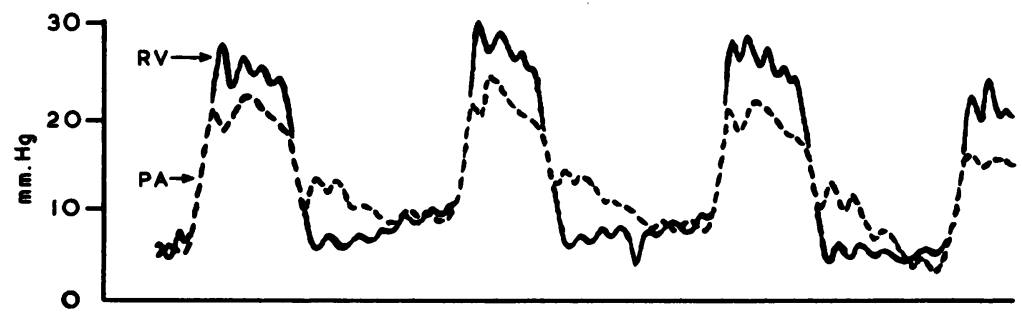

FIG. 1.-Superimposed pressure tracings from the pulmonary artery and the right ventricle. Care was taken to select records with identical heart rates from corresponding portions of the respiratory cycle. 


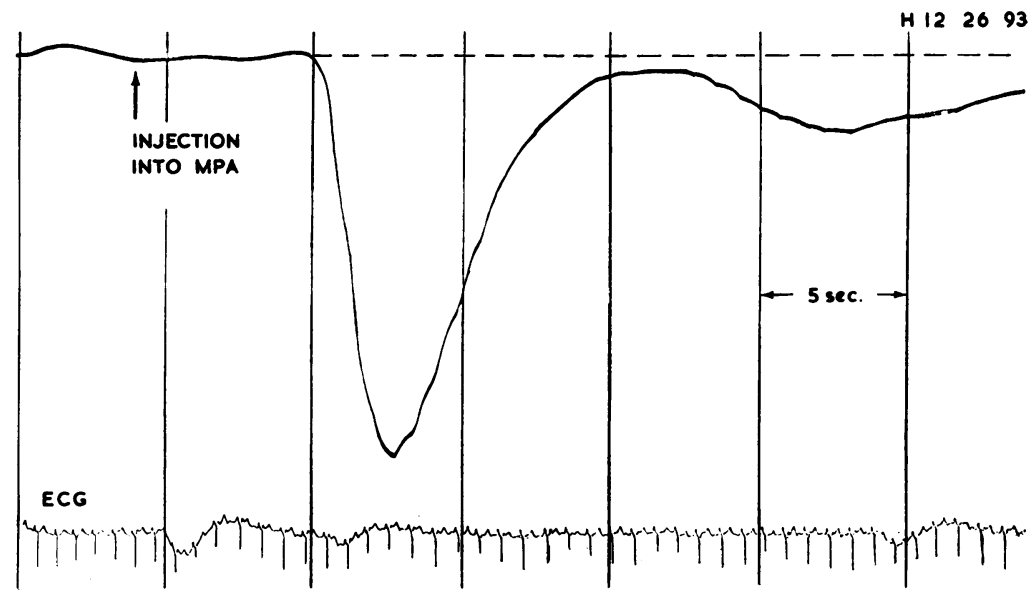

FIG. 2.-Indicator dilution curve recorded from the femoral artery following injection of $5 \mathrm{mg}$. cardio-green dye into the main pulmonary artery. Note the normal contours and slightly accelerated time components.

\section{Discussion}

The diagnosis of isolated pulmonary valvular regurgitation was strongly suspected on clinical grounds for the following reasons: the diastolic murmur was separated from the second heart sound by a short interval, it was low-pitched and rumbling, and it increased in intensity during inspiration. These characteristics, which have been described by Collins et al. (1960), Bousvaros and Deuchar (1961), and Laneve et al. (1962), help to distinguish the condition from pulmonary regurgitation secondary to pulmonary hypertension, in which the murmur characteristically, although not invariably (Wells, Rappaport, and Sprague, 1949), is protodiastolic, high-pitched, and decrescendo.

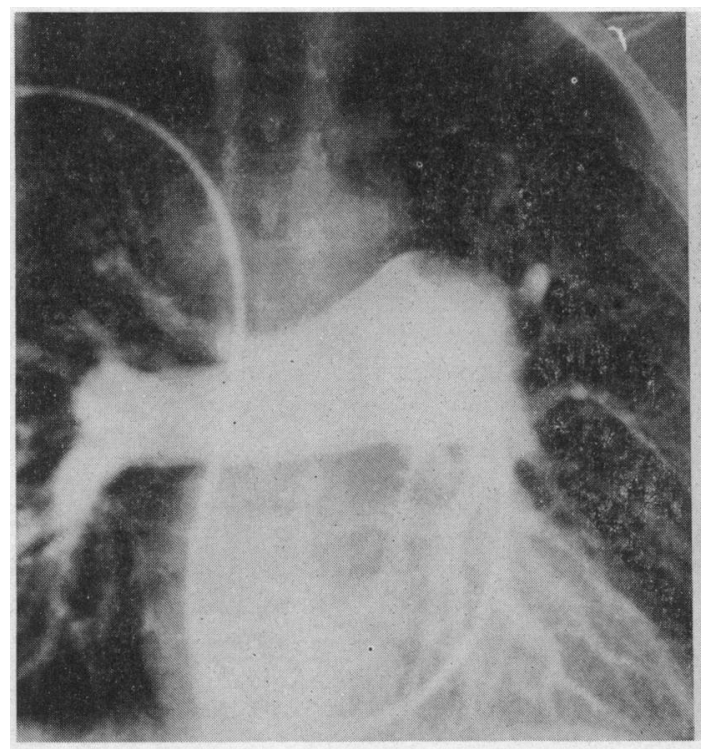

A

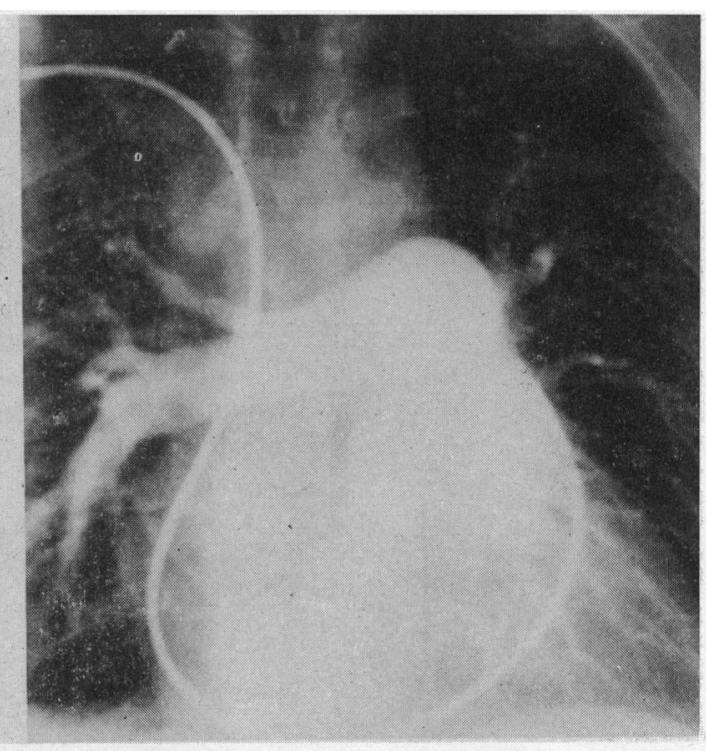

B

FIG. 3.-Arteriograms following injection of $30 \mathrm{ml}$. 90 per cent Hypaque into the main pulmonary artery; (A) systole, (B) diastole. Note the striking reduction in size of the right pulmonary artery and the opacification of the right ventricle during diastole. 
The systolic ejection click and murmur were readily explained by the rapid speed of ejection of blood into a widely dilated main pulmonary artery.

The right ventricle and pulmonary artery were found to be hyperdynamic, both on palpation of the præcordium and on fluoroscopy. The activity was similar to that of the left ventricle and the aorta in patients with free aortic regurgitation. The normal splitting of the second heart sound, the absence of any increase in the intensity of vascular markings in the peripheral lung fields and of the pattern of incomplete bundle-branch block in the electrocardiogram, helped to exclude atrial septal defect.

The absence of a history of rheumatic fever, or of any other unexplained pyrexial illness, provided supporting evidence against the diagnosis of an acquired disease.

Laboratory proof of the lesion was sought by cardiac catheterization and selective angiography. The systolic pressures in the right ventricle and pulmonary artery were normal, and the oxygen saturation data and indicator dilution curves provided no evidence for a shunt in either direction. The pressure in the pulmonary artery during the second half of diastole was equal to that in the right ventricle. There was a striking difference in the dimensions of the right pulmonary artery between systole and diastole (Fig. 3). The vertical dimension of the right pulmonary artery just proximal to the origin of its first branch was, during systole, 1.41 times that during diastole. Therefore, since the artery is circular in cross-section, the corresponding areas were in the ratio $1.41^{2}: 1$, or 1.99:1. In pulmonary arteriograms of 6 other patients from our files who had no abnormality of the outflow tract of the right ventricle or of the pulmonary valve, the ratios varied from 1.21:1 to 1.54:1.

Contrast dye injected into the pulmonary artery regurgitated into the right ventricle (Fig. 3). Inspection of the series of films showed that although the catheter tip moved back and forth, because of the hyperdynamic activity of the right ventricular outflow tract, it remained in the pulmonary artery. This was confirmed by pressure tracings taken immediately after the films were obtained.

The normal indicator dilution curves might at first sight appear surprising. In most patients with regurgitation due to disease of the mitral, aortic, and tricuspid valves the dilution curves show disproportionate prolongation of the disappearance slope and abnormal CL/CR ratios (Marshall, Woodward, and Wood, 1958). However, attempts to quantitate the severity of the regurgitation from the degree of distortion of the arterial dilution curve (Korner and Shillingford, 1955) have not been very successful (Novack and Schlant, 1958). This is due to the fact that, although to-and-fro flux of indicator across the regurgitant valve is certainly an important factor, other associated factors also contribute their degrees of distortion. These include reduced cardiac output, increased cardiopulmonary blood volume, and prolonged transit time between the heart and the arterial sampling site resulting from redistribution of systemic arterial blood flow (Marshall, 1962).

In the present case, these factors were not involved. The cardiac output was actually increased because of the coexistent thyrotoxicosis. The recirculation time $(15 \mathrm{sec}$.) was reduced, in part undoubtedly because of a rapid transit time through the arteries to the sampling site. The normal cardiac size and the absence of any increase in pulmonary vascular markings were evidence of a normal cardio-pulmonary blood volume. Further, to-and-fro flux of indicator across the pulmonary valve could have had little distorting effect since the right ventricle emptied well; no detectable opaque dye remained in it after three heart cycles $(1.8 \mathrm{sec}$.) following completion of the injection of Hypaque into the pulmonary artery.

The dilatation of the main pulmonary artery was so striking that it is impossible to be certain whether this was the cause or the result of the valvular regurgitation. Only a few patients with idiopathic dilatation of the pulmonary artery have the complication of valvular regurgitation (Segal et al., 1957). It is equally possible that the pulmonary artery may dilate secondary to the persistent high stroke output from the right ventricle, as it does in the presence of a normal pulmonary valve in patients with large atrial septal defects. As an analogy, it will be recalled that the proximal part of the ascending aorta is often widely dilated in patients with aortic regurgitation.

The absence of any symptoms, other than those attributable to the associated thyrotoxicosis, was consonant with the well-recognized benign course of most patients with pulmonary regurgitation 
(Laneve et al., 1962). Pulmonary regurgitation resulting from operations on the valve for the relief of congenital stenosis also usually causes little disability, and the heart shows little (Blount $e t$ al., 1954) or no (Swan et al., 1954) increase in size compared with other patients in whom identical operations did not result in regurgitation. Complete removal of pulmonary valve tissue in dogs is also usually well tolerated (Ellison et al., 1955), although in other series (Kay and Thomas, 1954; Fowler and Duchesne, 1958) dilatation and hypertrophy of the right ventricle have occurred. The reason appears to be that the right ventricle is a low-pressure pump; as Rushmer (1961) has emphasized, its configuration is such that it readily adapts to increasing volumes of blood with little lengthening of, or increase of, tension in its muscle fibres. However, conclusions drawn from the study of series of cases do not necessarily pertain to individual patients, and the possibility cannot be excluded that in the patient reported here the severity of the regurgitant lesion may eventually compromise the function of the right ventricle.

\section{Summary}

Hæmodynamic features are described in a patient with pulmonary valvular regurgitation complicated by thyrotoxicosis.

The association of these two conditions results in an unusual degree of hyperdynamic activity of the right ventricle and the pulmonary artery. The fact that the right ventricular end-diastolic pressure remains normal in the presence of an increased cardiac output at rest confirms previous clinical and experimental evidence that the valvular lesion is well tolerated.

Reasons for the finding of normal arterial indicator dilution curves, in contrast to the abnormalities usually found in the presence of regurgitation of other valves, are discussed.

In cases such as this, it is difficult to decide whether the dilatation of the pulmonary artery is secondary to the valvular lesion, or whether the valvular lesion is a result of idiopathic dilatation of the pulmonary artery.

\section{References}

Blount, S. G., Jr., McCord, M. C., Mueller, H., and Swan, H. (1954). Isolated valvular pulmonic stenosis: Clinical and physiologic response to open valvuloplasty. Circulation, 10, 161.

Bousvaros, G. A., and Deuchar, D. C. (1961). The murmur of pulmonary regurgitation which is not asscoiated with pulmonary hypertension. Lancet, 2, 962.

Collins, N. P., Braunwald, E., and Morrow, A. G. (1960). Isolated congenital pulmonic valvular regurgitation. Diagnosis by cardiac catheterization and angiocardiography. Amer. J. Med., 28, 159.

Ellison, R. G., Brown, W. J., Jr., Hague, E. E., and Hamilton, W. F. (1955). Physiologic observations in experimental pulmonary insufficiency. J. thorac. Surg., 30, 633.

Fowler, N. O., and Duchesne, E. R. (1958). Effect of experimental pulmonary valvular insufficiency on the circulation. J. thorac. Surg., 35, 643.

Kay, J. H., and Thomas, V. (1954). Experimental production of pulmonary insufficiency. Arch. Surg., $69,646$.

Korner, P. I., and Shillingford, J. P. (1955). The quantitative estimation of valvular incompetence by dye dilution curves. Clin. Sci., 14, 553.

Laneve, S. A., Uesu, C. T., and Taguchi, J. T. (1962). Isolated pulmonic valvular regurgitation. Amer. J. med. Sci., 244, 446.

Marshall, H. W., Woodward, E., Jr., and Wood, E. H. (1958). Hemodynamic methods for differentiation of mitral stenosis and regurgitation. Amer. J. Cardiol., 2, 24.

Marshall, R. J. (1962). Special article. Factors modifying the contours of indicator-dilution curves. Circulat. Res., 10, 123.

Novack, P., and Schlant, R. C. (1958). Korner-Shillingford method for estimating regurgitant flow. In Methods in Medical Research, Editor-in-chief, J. V. Warren. Year Book Publishers, Chicago.

Rushmer, R. F. (1961). Cardiovascular Dynamics, 2nd ed. Saunders, Philadelphia and London.

Segel, N., van Lingen, B., Resnekov, V., and McGregor, M. (1957). Isolated congenital pulmonary incompetence. S. Afr. med. J., 31, 1157.

Swan, H., Cleveland, H. C., Mueller, H., and Blount, S. G., Jr. (1954). Pulmonic valvular stenosis. Results and technique of open valvuloplasty. J. thorac. Surg., 28, 504.

Wells, B. G., Rappaport, M. B., and Sprague. H. B. (1949). The graphic registration of basal diastolic murmurs. Amer. Heart J., 37, 586. 